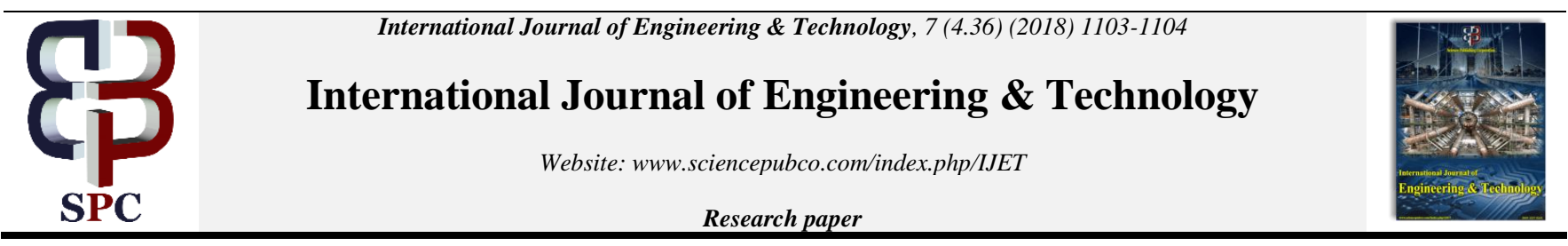

\title{
Application of Universal and Disciplinary Design
}

\author{
Sokolova M.L. \\ MIREA - Russian Technological University, Moscow, Russia
}

\begin{abstract}
The present paper deals with problems of applying universal and disciplinary design both in design of individual products and devices, and in formation of environmental elements. Recommendations are given on the use of the principles of universality and disciplinary as the main governing principles of design, as well as on the formation of competence in the use of universal and disciplinary design. When training specialists in the field of design.
\end{abstract}

Keywords: Disciplinary Design, communicative design, Optimization

\section{Introduction}

In recent years, a number of organizations and departments in Russia - ministries, institutes, public associations including associations of disabled people, has begun active work on introducing universal design principles into the formation of a subject-spatial environment, programs, availability passports, contests and competitions for designers, etc. At the same time, less attention is paid to the principles of disciplinary design, which are the second necessary aspect of the created environment.

The principles of universality in design ensure the formation of a subject-spatial environment suitable and convenient without special adaptation for use by various categories of citizens. At the same time, various categories include adults and children, healthy people and people with disabilities, permanently and temporarily disabled, pedestrians and drivers, cyclists, pet owners, etc. The principles of disciplinary protection protect certain categories of the population, for example, pedestrians, children, disabled people, etc. from the danger of using or contacting with any elements of the subject-spatial environment. Therefore, universal design can be defined as a design that takes into account the needs of a minority, and a disciplinary one that takes into account the needs of the majority.

You can put in accordance with the principles of universality and disciplinary ergonomic approach, which received scientific substantiation in the 60 s of the 20th century. When it was proposed to base the entire design on the distribution of anthropometric data. It was at this time that the usual sizes of most products - clothes, furniture, buildings, etc. - were formed. The formation was carried out on the basis of statistical data. For example, the height of entry and exit should be convenient for most people, and therefore were calculated based on the distribution of people's height values according to the 95th percentile so that most people (95 percent) can use it freely $[1,2]$. Today, there is a similar formation of rules and regulations that ensure a comfortable existence of people, but at a higher, more general from the standpoint of design level, based on the principles of universality and disciplinary.

\section{Research Method}

As a methodological basis, a systematic approach is applied, which involves a comprehensive consideration of the subject of study. To obtain analytical data, a comparative analysis method was used.

Minimizing the time of surgery and improving the patient's health is critical to reducing the financial burden created for the healthcare system and patients, while improving treatment outcomes. This goal has led to new advances in medicine and in particular in the area of personalized treatment options. New technologies such as incremental buildup and digital 3D modeling have had a positive impact on pre-operative planning and treatment areas and have led to the creation of customizable auxiliary devices that can be adapted to the body, such as resection guidelines Surgery, surgical planning models, and anatomical educational aids and, of course, jaw prosthesis. In the past few years, the US Food and Drug Administration has increased its commitment to 3D-based implants under a system of pre-sales notices, which allow incremental build-ups to be made in practice Surgical and complex surgery.

To analyze application of the principles of universality and disciplinary, it is advisable to single out three large areas of design including: environmental design, as a design that forms spaces; communication design that provides social contacts; and industrial design involved in the preparation of facilities for industrial production. The basis of this division is the main function performed by the design object in each of the listed areas. Further classification within these areas will be based on different classification features - environmental design depends on the objects of application of forces (landscape design, interior design, etc.) communicative is determined the way of contact or its purpose (web design or printing, advertising or social, etc.), industrial is associated with the method of production of products in various industries. But in all areas of design, the principles of universality and disciplinary are governors and should be laid at a higher level, at the level of the main areas of focus. 


\section{Results and analysis}

Analysis of the formation of modern object-spatial environments shows that problems of understanding these principles are gradually accumulating, both at the level of organizations and at the level of individual individuals. This is often associated with an attempt to replace the concept of "universality" with the concept of "accessibility under certain conditions." Certain conditions are the special appeal of the individual to the organization, which is unacceptable from the point of view of universal design. Society must take into account the principles of universality in the formation of both individual products and environments without special treatment, as a manifestation of their humanity.

It should be noted that often in the design and creation of the objective environment, including such areas as residential, industrial and public buildings, utilities, transport, medicine, light industry products, information and communication sphere, etc., the principles of universal and disciplinary design so far they are not laid at the design stage, but are an additional, often purely decorative addition. There is no generally accepted system of indicators to monitor the application of the principles of universal design, there are no methods for their measurement and technologies of use. Moreover, in some cases, work on the formation of a barrier-free and protective environments are harmful and distort the aesthetics of existing objects, interfere with their normal functioning and constructively not justified. And aesthetics and functionality are concepts that should not be opposed, since they are aspects of a single whole.

Analyzing the distribution of the governing principles (universality and disciplinary) in each of the selected areas, it can be noted that they are most widely used in environmental design. This may be due to the greater need for the formation of comfortable living conditions. But in the field of communicative design, the smallest consideration of these governing principles is noted, which may be related to the development of this area in the direction of audience targeting and the constant search for target audiences, which narrows the effect of general governing principles. As regards the application of these governing principles in the field of industrial design, but there is a very ambiguous situation, which is determined, in our opinion, by two factors. First, the level of development of various industries, their humanization and, secondly, training [3], with the competence to introduce universal and disciplinary design in the structure of products, both through the search for new forms, and through the modification of existing ones.

The universal design is based on the principle of accessibility, but not "on demand" of an individual or a public association, but as a natural opportunity given in a universally formed environment. Moreover, we should not forget about the time taken into account principles of universality and disciplinary. This must be the design stage. And now, even in the most favorable area - design of spaces - the formation of accessibility and protection is often not taken into account when preparing technical specifications, and, therefore, they are not developed in design and production, leaving them to the maintenance and repair departments.

There are two main areas of work that should help eliminate the identified problems:

- educational work: promotion and study of the principles of universal and disciplinary design, both through various traditional stationary forms of training, and through short-term forms of retraining, including selected thematic lectures, seminars, empathy laboratories;

- scientific work: the formation of an integrated system for assessing the subject-spatial environment based on the principles of universal and disciplinary design.

\section{Conclusion}

It is concluded that, the main governing principles of design universal and disciplinary - should be taken into account when shaping, modifying and decorating all objects of subject-spatial environments, and their dissemination should be facilitated by the training of designers with appropriate competence in applying universal and disciplinary design.

\section{References}

[1] V.I. Kumanin, The evolution of design in Russia in the last century, Proceedings of the Academy of Technical Aesthetics and Design. 2013. №1. Pp. 29-30.

[2] V. Papanek, Design for the real world. M .: D. Aronov, 2004. 416s.

[3] M.L. Sokolova, Modern problems of the direction "Technology of artistic processing of materials", Russian technological journal.2017. v.5. № 1. S. 50-56.

[4] A.Y. Albagachiev, I.Yu. Mamedova, N.E. Milchakova, M.L. Sokolova. Industrial design and the application of the principles of universality in the design of technical products // Bulletin of mechanical engineering. 2018. No. 11. P.84-86 